\title{
COLLABORATIVE SERVICE-DOMINANT BUSINESS MODEL DESIGN FOR A JUST-IN-TIME RAIL SHUTTLE SERVICE AT THE PORT OF VALENCIA
}

\author{
C. PÉREZ-CERVERA ${ }^{1}$, M. LU², A. SÁNCHEZ-PÉREZ ${ }^{1}$, L. SÁEZ-CARRAMOLINO ${ }^{1} \&$ \\ S. FURIÓ-PRUÑONOSA ${ }^{3}$ \\ ${ }^{1}$ Project Manager at Fundación Valenciaport (Spain) \\ ${ }^{2}$ Dynniq Nederland B.V. (The Netherlands) \\ ${ }^{3}$ Director of Innovation \& Port Cluster Development at Fundación Valenciaport (Spain)
}

\begin{abstract}
Given the growth in container transport volumes and the use of mega-ships calling at a limited number of hub ports, it is necessary to increase the capacity of port-hinterland connections. Rail transport should play a key role in providing a sustainable response to this need and innovative solutions must be developed which can address the current problems and limitations through a more collaborative approach involving all the relevant stakeholders. The present study contributes to the development of an innovative Just-In-Time Rail Shuttle Service for a major port-hinterland corridor of the Port of Valencia (Valencia-Zaragoza) and its service-dominant business logic, which emphasises the interaction between different transport agents as they co-create value through collaborative processes. The servicedominant business model radar (SDBM/R) methodology has been applied in close collaboration with industry experts and the resulting model evaluated through an extensive series of hands-on workshops with industry professionals from the port and logistics sector. This paper focuses on the application and evaluation of this methodology in the inland container transport domain, aimed at harnessing digital innovation in the design of new business models for a Just-In-Time Rail Shuttle Service. In summary, it contributes a novel and collaborative business design approach that has an academic grounding and practical relevance.
\end{abstract}

Keywords: Business models, Collaborative value co-creation, Digital innovation, Intermodality, Just-in-time, Rail shuttle, Rail transport, Service-dominant business model.

\section{INTRODUCTION}

Volume peaks in certain hub ports, mainly due to the continuous growth in the size of containerships, put more pressure on port-hinterland connections, which require higher capacity and more efficient processes to accommodate cargo [1]. Road, rail and inland waterways have to respond effectively to cargo concentration. In Europe, road transport represents the highest share of port-hinterland connections. Thousands of trucks call at port and terminal gates daily, which typically gives rise to port congestion, delays, queuing and long dwell times for ships and cargo at the port, besides other externalities [2]. This ultimately means extra costs and negative environmental impacts [3].

In response to the adverse effects of road transport, ports are developing multiple strategies and policies to improve their port-hinterland connections, considering other transport modes such as rail and inland waterways. In this respect, rail freight transport can play a key role in improving port-hinterland connectivity as it currently represents a low modal share in several European countries [4]. In its 2011 White Paper on Transport, the European Commission set a target for modal shift from road to rail of $30 \%$ of the current freight tonnage transported over $300 \mathrm{~km}$ by 2030 , and $50 \%$ by 2050 [5], presenting a huge opportunity for rail freight transport to increase its modal share. 
To achieve this ambitious target, the main challenge is to attract shippers to use rail, which is directly linked to cost and time reduction. This requires the improvement of rail infrastructures and longer trains to reduce the cost per unit transported; more efficient processes that help to minimise handling movements; new Information and Communication Technology (ICT) solutions to speed up information exchange between the parties involved; and better planning of loading/unloading operations. Moreover, there is a need for new business models that can help to reduce operational costs and foster the use of rail freight transport.

In this context, a study has been carried out with the objective of analysing the feasibility of an innovative Just-in-Time (JIT) Rail Shuttle Service for a key port-hinterland corridor of the Port of Valencia (the 355-km-long Valencia-Zaragoza corridor), although the resulting business model can be replicated in other rail corridors.

The proposed JIT Rail Shuttle Service would operate similarly to an air shuttle, travelling back and forth at regular intervals on a particular route, with containers being loaded on the first shuttle available. This innovative rail service for container cargo would be the first of its kind in Spanish ports. The JIT Rail Shuttle will minimise handling movements in port container terminals by directly unloading containers from the vessel and loading them onto trains. To that end, before a container vessel calls at the port, port terminals will know which containers will be directly loaded onto the first available JIT rail service, eliminating the container storage in the terminal yard and reducing housekeeping movements of containers. This directly results in a reduction of unproductive container movements in container terminals. Finally, container terminals can reduce the environmental footprint of containers thanks to the reduction of container movements in loading/unloading operations, which means less energy consumption, but also thanks to the modal shift towards cleaner transport modes (from road to rail). All this is enabled by the implementation of innovative business models supported by disruptive technologies.

Indeed, this paper focuses on the design of the business model for this innovative solution. It is based on the Physical Internet concept, in which supply chain actors are interconnected in a network through which information is transferred and shared, maximising the efficiency of operations and minimising inefficient processes. Business models determine the value proposition of a given product or service, how it will be exploited, the main customers and partners, and the main sources of revenue and marketing channels. In the case of the JIT Rail Shuttle Service, a proposed business model based on the basic principles of the Physical Internet was assessed following an innovative business model design approach with members of the port community of the Port of Valencia as well as external experts.

\section{JUST-IN-TIME RAIL SHUTTLE SERVICE}

This section summarises the main results of the optimal solution (physical and operational) of the JIT Rail Shuttle Service for the port-hinterland connection in this case study: the rail corridor between the Port of Valencia and Zaragoza for container traffic. Full details of the JIT Rail Shuttle Service can be seen in Sáez-Carramolino et al. [6] and [7].

As previously mentioned, one key factor attracting shippers to use rail freight is the cost reduction achieved by minimising handling movements. Therefore, the optimal solution was the one that minimised the cost per TEU (twenty-foot equivalent unit) transported. The methodology proposed for the design of the optimal JIT rail freight solution involved the following steps: (1) Inputs and hypotheses; (2) Optimal composition model; (3) Cost analysis; (4) Sensitivity analysis. Furthermore, the information systems required for the implementation of this new service were also assessed in this study. Finally, an initial business model 
structure was proposed as the basis for the collaborative business model design using the Service-Dominant Business Model Radar (SDBM/R) methodology.

\subsection{Inputs and scenarios}

Several inputs were required to design an optimal operational solution for the JIT Rail Shuttle Service. The input variables considered related to the following categories: railway route characteristics; type of traffic and container types; types of locomotives and wagons; different train operational possibilities; a set of train compositions; and economic variables such as railway charges as well as financial data.

Subsequently, a set of seven scenarios were defined based on the aforementioned variables, with the differences among the scenarios being expressed in terms of the following variables:

- TRAFFIC-CONTAINER TYPE: Container composition; Full containers; Full ITU weight; ITU tare weight; Full TEU weight.

- LOCOMOTIVE: Locomotive type; Maximum towable load; Locomotive acquisition value; Locomotive annual depreciation.

- TRAIN OPERATION: Roundtrips per day; Total annual distance covered; Train drivers.

- TRAIN COMPOSITION: Composition number.

Full details of the inputs and scenarios are explained in the JIT Rail Shuttle Service feasibility study carried out in the COREALIS project and can be seen in Sáez-Carramolino et al. [6] and [7].

\subsection{Optimal composition model}

The optimal composition was obtained in two steps: firstly, maximising the capacity and secondly minimising the total tare weight of the train composition.

First step:

$$
\operatorname{Max} C=\sum_{\forall i} n_{i} \cdot c_{i}
$$

Subject to:

$$
\begin{aligned}
& \sum_{i} n_{i} \cdot k_{i}+\sum_{i} n_{i} \cdot c_{i}(\varphi \cdot \sigma+(1-\varphi) \cdot \omega) \leq T \text { (max towable load limit) } \\
& \alpha \sum_{i} n_{i} \cdot c_{i} \geq n_{60^{\prime}} \cdot \text { (limit of } 60 \text {-foot wagons in order to avoid empty spaces) } \\
& \sum_{i} n_{i} \cdot l_{i} \leq L \text { (max length limit) }
\end{aligned}
$$

Parameters and variables on train composition:

- $i=$ type of wagon $i \in\left\{40^{\prime} ; 60^{\prime} ; 80^{\prime} ; 90^{\prime}\right\}$

- $n_{i}=$ number of wagons of type $i$ (decision variables)

- $c_{i}=$ capacity in number of TEU of one wagon of type $i$ 
- $k_{i}=$ tare weight of one wagon of type $i$

- $l_{i}=$ length of one wagon of type $i$

- $T=$ maximum towable load (depends on the locomotive and the maximum slope on the route)

- $L=$ maximum length of the train composition allowed on the route

- $C=$ train capacity in number of TEU.

Parameters and variables on traffic composition

- $\varphi=$ percentage of full TEU

- $\alpha=$ percentage of 20 foot containers

- $\sigma=$ average weight per TEU for full containers

- $\omega=$ average tare weight per TEU for empty containers

Second step:

Subject to:

$$
\operatorname{Min} \sum_{\forall i} n_{i} \cdot k_{i}
$$

$$
\sum_{i} n_{i} \cdot c_{i} \geq C .(\text { min capacity limit })
$$

Solving this problem, the optimal solution for the defined scenarios was to use 80 -foot wagons, which allowed three different combinations of 20 -foot and 40-foot containers $\left(4 \cdot 20^{\prime}\right.$, $2 \cdot 40^{\prime}$ or $20^{\prime}+40^{\prime}+20^{\prime}$ ).

\subsection{Cost analysis}

The next step after defining the optimal composition with the number and type of wagons for each scenario was to carry out a cost analysis from the point of view of the railway undertaking that operates the JIT Rail Shuttle. This annual cost analysis identified the scenario that minimised the cost per TEU transported, which is directly linked to the charges faced by the end customer.

The variables accounted for in the cost analysis included railway charges; fixed costs such as the annual locomotive depreciation or the composition acquisition value; variable costs such as fuel consumption or maintenance; terminal costs; and other costs.

The results of the feasibility study showed that the cost per unit transported decreased when the train capacity and length increased, as well as when the number of weekly roundtrips rose [6] and [7]. Thus, the scenario that minimised the cost per TEU transported maximised train capacity and length and considered three roundtrips per day to cover the traffic demand in the selected corridor (EUR 93.29 per TEU transported). However, given that the JIT Rail Shuttle Service will be the first to operate in Spain, a more realistic option for getting it operative in the short term would be a scenario with only two roundtrips per day, five days a week, with 475-metre-long trains and a cost per TEU transported of EUR 95.37.

\subsection{Sensitivity analysis}

To complete the cost analysis of the JIT Rail Shuttle Service, the feasibility study included a sensitivity analysis on the cost per TEU transported ( $€ / T E U)$. To that end, a stochastic simulation was applied to the different cost variables of the scenarios assessed, applying an average 
value for each parameter along with a confidence interval using the minimum and maximum expected values for each variable and a probability distribution of the expected changes in the parameters. The probability distributions used for each of the cost variables were:

- Normal distribution: wagon acquisition cost, wagon maintenance cost, locomotive rental cost, driver annual cost, fuel cost, daily locomotive substitution cost, terminal handling costs (inland and maritime), percentage of terminal transhipment movements and other costs.

- Weibull distribution: locomotive fuel consumption.

- Uniform distribution: ACA Services.

- Triangular distribution: locomotive acquisition cost and train occupancy

- Discrete uniform distribution: locomotive and wagons lifecycle, daily roundtrips and number of compositions.

In the sensitivity analysis carried out, the strongest determinants of the cost per TEU transported were the Terminal Handling Charge (THC) at port terminals, with a positive sign $(18.2 \%)$; the Occupancy composition $(\%)$, with a negative sign $(-17.6 \%)$; the Fuel Price, with a positive sign (11.8\%); the Additional, Complementary and Auxiliary (ACA) services charge, with a positive sign (11.7\%); the Inland Terminal Handling Charge, with a positive sign $(8.2 \%)$; Daily roundtrips $(-5.6 \%)$; and Composition number $(-5.6 \%)$. The rest of the variables assessed in the sensitivity analysis accounted for separately less than $5 \%$ of the variance of the cost per TEU (both positive and negative signs).

\subsection{Information requirements}

A key factor for the success of the JIT Rail Shuttle Service is the use of ICT tools for the information exchange between the parties involved in the vessel-train operation. In the Port of Valencia, the different agents involved in container operations use the Port Community System (PCS), called ValenciaportPCS, as an open and neutral electronic platform that allows the safe exchange of information between them and also increases the efficiency of port processes [8]. In this particular case, the main documents exchanged are Transport orders (Transport Instructions), Acceptance/Release orders, Train Loading/Discharge List and Train Composition.

The new JIT Rail Shuttle Service will require additional information exchanges that affect the current information flows between the different agents. Container terminals currently receive the information about the containers to be loaded onto a train by electronic means, but this information is received after the containers are discharged from the vessel. Therefore, import containers must stay in the container yard before they are transported to the rail terminal. In order to prevent such inefficient movements, the JIT Rail Shuttle Service will require this information to be provided prior to the vessel unloading operation so that when the containers are being discharged they can be transported directly to the rail terminal. Thus, in the proposed information exchange procedure, shipping agents will have to indicate in the Discharge List which containers should be loaded onto the JIT Rail Shuttle Service. The container terminals will then generate a Shuttle Loading List and will share it with the railway company through the PCS for it to be validated before starting loading operations. The final Loading List will subsequently be shared with all the different agents involved in the logistics chain. 
The new information exchanges between container handling parties via the PCS enable an increase in the overall operational efficiency. Port terminals are able to reduce unproductive container movements, optimise their yard capacity and loading/unloading container processes and also reduce the environmental impact of container handling operations.

\subsection{Business model proposed for the JIT Rail Shuttle Service}

Finally, the JIT Rail Shuttle Service feasibility study proposed a business model in which an entity called "SHUTTLE" is created to manage the capacity of the service. The SHUTTLE authority is the entity that owns the locomotives and wagons and manages the "slots" (spaces on the train) that are sold to the different railway operators. On the one hand, the SHUTTLE company issues tender contracts to selected railway undertakings interested in operating the JIT Rail Shuttle Service at a certain price while maintaining an established quality of service. On the other hand, the SHUTTLE authority opens bidding processes to sell the available slots among the interested railway operators or freight forwarders. Rail operators or freight forwarders bid for the rights to trade a certain percentage of the available slots on the shuttle. The SHUTTLE authority then studies the offers and chooses the best bids (those that guarantee the lowest $€ / T E U$ for shippers).

\section{BUSINESS MODEL DEVELOPMENT METHOD}

Traditionally, the Business Model Canvas (BMC) has often been used for business model development [9]. Although this method is easy to use, it has some drawbacks. BMC follows an organisation-centric approach and renders the model from the perspective of a single company. In today's business world, customer-oriented solutions involve multiple parties. Furthermore, BMC focuses on the processes controlled by the focal company, but pays no attention to the customers' active role in value co-creation. Moreover, BMC relates more to the "strategic" considerations of a focal company, and less to the operational aspects of a particular solution scenario involving multiple parties and providing concrete benefits to a specific customer segment.

This paper relies on the SDBM/R method, which overcomes the aforementioned drawbacks or limitations of the BMC, and is appropriate for the development of business models in the logistics sector involving multiple actors in a collaborative environment, as is the case with the JIT Rail Shuttle Service. The method is based on the framework of BASE/X (Business Agility through Service Engineering in a Cross-Organizational Setting) developed by Grefen [10], which has been successfully used in transport and logistics domains [10]-[17]. A service-dominant business model identifies the added value of the service to the customer or user, the functions and capabilities required by each party (e.g. organisations, institutions, companies and customers) participating in the model, as well as the expected costs and benefits. The business models for a service (or a coherent collection of services) provide a solid basis for the requirements for the solutions, and a cost-benefit analysis for such solutions. A qualitative comparison between the BMC model and the SDBM/R model is presented in Table 1.

BMC and SDBM/R are completely different approaches for business model development. BMC is a very solid, powerful method. However, when it comes to studying the feasibility of a new service with multiple actors, SDBM/R offers advantages for the corresponding business model development. This paper does not aim to carry out a comparative study of the two methods, but rather to examine a proposed JIT Rail Shuttle Service at the Port of 
Table 1: Comparison between BMC and the SDBM/R.

\begin{tabular}{lll}
\hline & Business model canvas (BMC) & $\begin{array}{l}\text { Service dominant business model } \\
\text { radar (SDBM/R) }\end{array}$ \\
\hline Basic concept & $\begin{array}{l}\text { Follows an organisation-centric } \\
\text { approach, and renders the model } \\
\text { from the perspective of a single } \\
\text { company. }\end{array}$ & $\begin{array}{l}\text { Concerns customer-oriented } \\
\text { solutions involving multiple } \\
\text { business actors and potential } \\
\text { collaborations between them. }\end{array}$ \\
$\begin{array}{ll}\text { Focuses on the processes } \\
\text { controlled by the focal company, } \\
\text { but not on the customers' active } \\
\text { role in value co-creation. } \\
\text { Relates more to the strategic } \\
\text { aspects of a focal company, and } \\
\text { less to the operational aspects of a } \\
\text { particular solution scenario. }\end{array}$ & $\begin{array}{l}\text { Focuses on the customers' active } \\
\text { role in value co-creation. }\end{array}$ \\
& $\begin{array}{l}\text { Practically relates to the operational } \\
\text { aspects of a particular solution } \\
\text { and providing concrete benefits to a } \\
\text { secific customer segment. }\end{array}$ \\
Ease of use & $\begin{array}{l}\text { Needs guidance, a facilitator } \\
\text { and participants from the key } \\
\text { parties to ensure the quality of the } \\
\text { implementation }\end{array}$ \\
\hline
\end{tabular}

Valencia involving multiple actors (e.g. the port authority, terminal operator, rail shuttle infrastructure provider, JIT Rail Shuttle Service providers, shippers, transport companies and IT companies), for which collaboration among the actors is a must. The rationale for choosing $\mathrm{SDBM} / \mathrm{R}$, from business perspective, is based on the characteristics of the method and the advantages of using SDBM/R for developing a collaborative business model with multiple actors.

SDBM/R has a network-centric design at its core, allowing the composition of service design in multi-party business networks. It defines how the actors in the business ecosystem participate in value co-creation and identifies the cost-benefit distribution [14]. Figure 1 presents the elements of the SDBM/R. The co-created value-in-use constitutes the central point in SDBM/R. Following service-dominant thinking, it represents the value of a solution to a customer.

The first concentric layer framing the value-in-use contains the actor value propositions, which represent the part of the central value-in-use contributed by a single actor. The coproduction activity defines the activities that each actor performs in the business to achieve the co-creation of value, i.e. its actor value proposition. The effects of this activity are observable by the customer. The third frame - actor cost/benefits - defines the financial and non-financial expenses/gains of the co-creation actors. Finally, each "pie slice" of the radar represents a co-creation actor, including the focal organisation, core and enriching partners, and the customer.

The labels of the actors are in the fourth frame. The focal organisation is often the party that initiates the setup of the business model, and participates actively in the solution. The customer is always one of the parties contributing to the production of the value-in-use. 


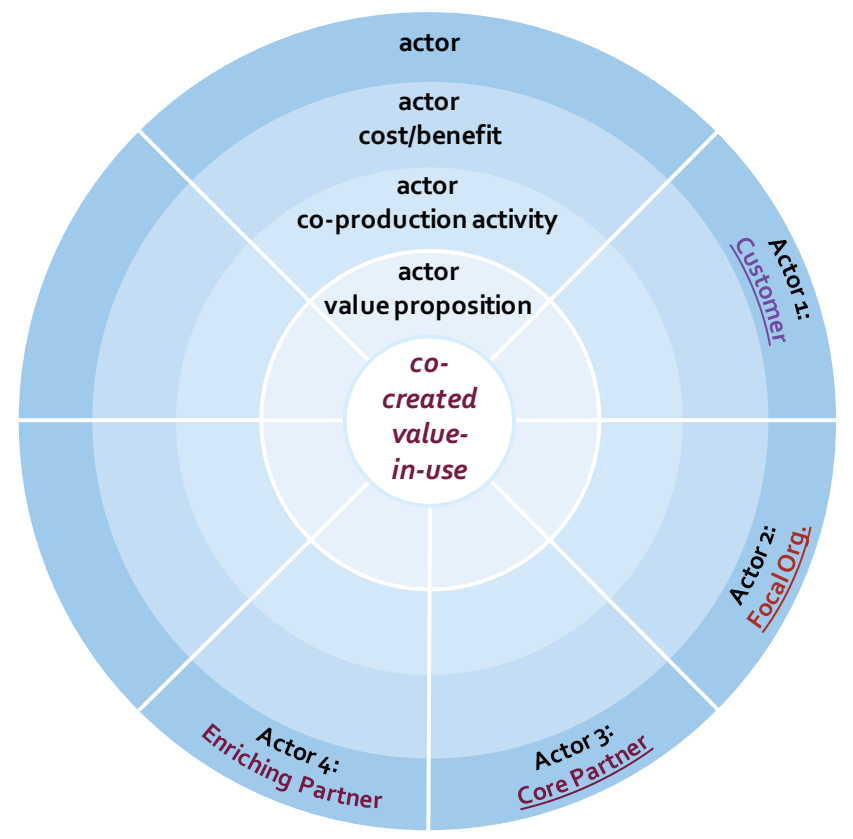

Figure 1: Service-dominant business model radar (SDBM/R) template.

A core partner contributes actively to the essentials of the solution, while an enriching partner enhances the solution's added value-in-use. SDBM/R accommodates an arbitrary number of actors, suiting the network-centric character of a service-dominant business. The provision of logistics solutions can be analysed from a service-dominant perspective and typically involves many actors (either direct or indirect) in multi-sided business models.

The business model design using SDBM/R should be done as an iterative process even though it entails the following sequential steps: (1) identify and agree on the co-created value-in-use; (2) describe the customers; (3) determine the components of the value-in-use (actor value propositions) and associated actors (roles); (4) identify the costs and benefits for each actor; and (5) define the activities that each actor realises for the actor-value proposition. This sequential order can be revised during the workshop sessions and it is typically the case that determining the actors' costs and benefits (step 3) influences the decisions made in the preceding steps. The next section describes an initial set of business models resulting from the workshop organised with several stakeholders in the logistics domain.

\section{BUSINESS MODEL DEVELOPMENT FOR THE JIT RAIL SHUTTLE SERVICE}

A workshop was conducted to develop an appropriate business model for the JIT Rail Shuttle Service. The aim was to collaboratively design business models with the relevant actors for this specific logistics service, relying on the SDBM/R to do so.

The workshop brought together relevant stakeholders at the Port Authority of Valencia (PAV), including representatives of the PAV, terminal operators, technology/service providers, a rail operator, as well as experts from academia, foundations and associations.

The workshop was divided into two phases. The first phase consisted of the presentation of the main outcomes of the JIT Rail Shuttle Service feasibility study. The moderator also 
presented the theory and the SDBM/R method to the workshop participants. The second phase comprised the interactive design of a specific business model using the SDBM/R, under the guidance of the business model design moderators.

During the second part of the workshop, the participants first identified value-in-use, i.e. the added value for the customer. Participants from the public sector and from the private sector may have different views, but in a collaborative model, an agreement has to be reached. Workshop participants agreed that efficient, green transport was the co-created value-in-use. The next step was to determine the actors, especially the Customer, Focal Organisation, Core Partner and Enriching Partners. The participants agreed to identify the shipper as the Customer, an orchestrator as the Focal Organisation, a Logistics Service Provider (LSP) as the Core Partner, and a rail operator and the government as Enriching Partners. Additional Enriching Partners could be incorporated as needed. Due to the time limitation of the workshop (it lasted around one and a half hours), not all the relevant actors could be analysed. The workshop started with the following actors, e.g. Shipper, Orchestrator, LSP, Rail Operator and Government/Regulator. Participants recognised that Valencia was still lacking a key actor Orchestrator, that is, the "SHUTTLE" entity presented in section 2.6, needed to make the business model work. Other actors, such as Terminal Operator, Port Authority, Railway Infrastructure Provider, Shipping Line, Customer, Citizen and Customs were considered, but the workshop did not involve a detailed analysis of these actors. The workshop results are presented in Fig. 2.

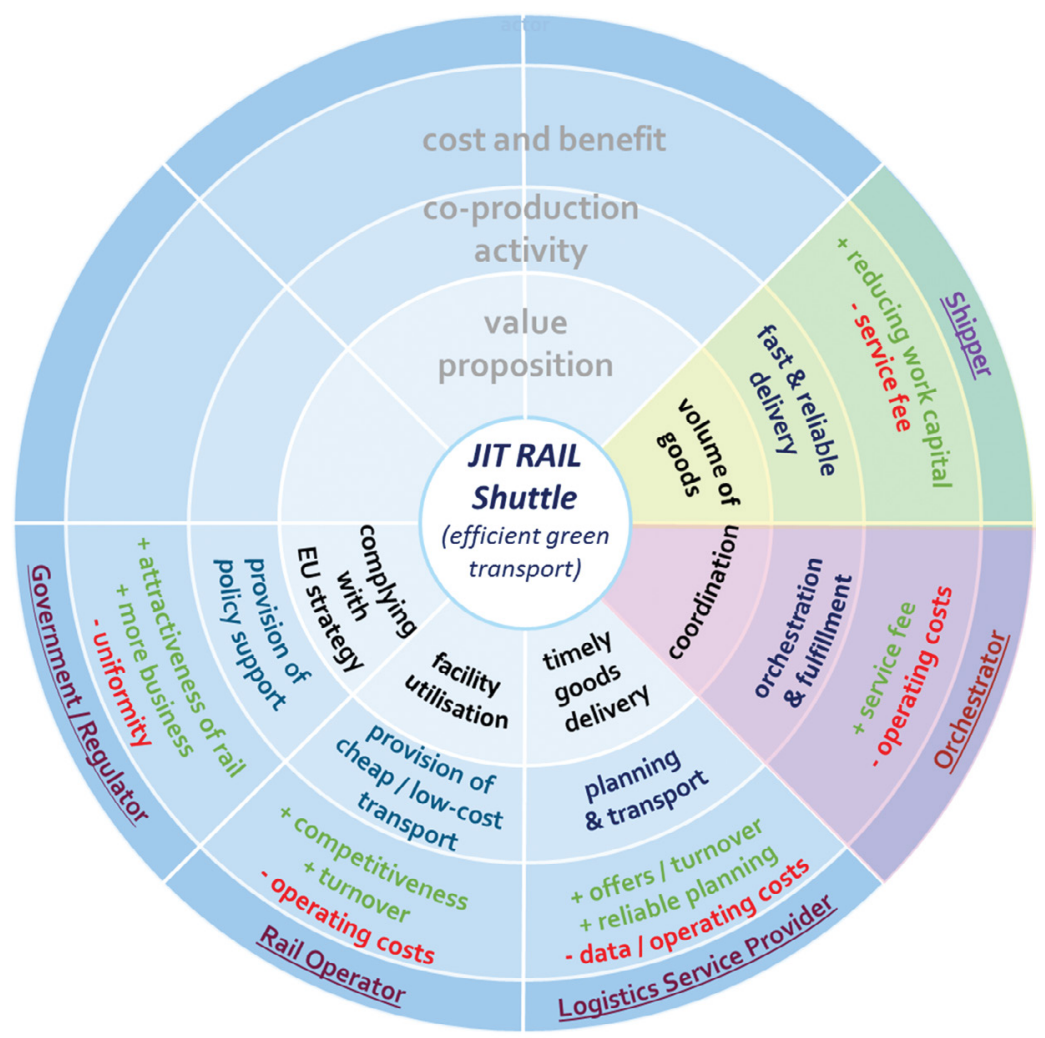

Figure 2: JIT Rail Shuttle Service SDBM/R. 
For each main selected actor, the following procedure was applied:

1. Define the value proposition of each actor, i.e. what elements the parties in the network contribute to the value-in-use. This is also crucial for the collaborative business model development. The workshop participants determined that, in this case, the value proposition for a shipper is the volume of goods, for an orchestrator it is coordination, for an LSP it is on-time delivery, for a rail operator it is facility utilisation, and for a government it is compliance with the European Union sustainability strategy.

2. Identify the co-production activity of each actor, i.e. which activities the network parties must perform in collaboration to realise the value-in-use. This is a very straightforward task for experts in the domain. The workshop provided valuable opportunities for different actors to think about each other's roles, to understand each other better, and to learn from each other. In this case, the co-production activity identified for a shipper is fast and reliable delivery, for an orchestrator it is orchestration and fulfilment, for an LSP it is planning and transport, for a rail operator it is provision of cheap transport, and for a government it is provision of policy support.

3. Identify costs and benefits for each actor (financial and non-financial), and determine whether this leads to a viable business network. During the workshop, only qualitative analysis were conducted so it would be valuable for the actors to further quantify the costs and benefits. The benefit for a shipper is reduction of work capital, but the shipper needs to pay a price for this, i.e. the service fee. An orchestrator benefits by charging a service fee, but it needs to cover its own operating costs. An LSP may increase supply services (therefore increasing its turnover), but the LSP needs to cover its own operating costs and to get relevant data. The benefit for a rail operator is a gain in competitiveness and increased turnover, but the rail operator needs to cover its operating costs. A more attractive and competitive rail sector and more business is the benefit for the government.

While a good start has been made on developing the business model for the JIT Rail Shuttle Service, it should be noted that one workshop does not provide a fully fledged implementation of the method. For instance, quantification of the costs and benefits, as well as other related issues (such as fairness, investment period, time constraints) still need to be further discussed by the local stakeholders. The business model needs to be finalised by analysing all the relevant key actors, detailing the actions of the key actors, and quantifying the costs and benefits of each actor. The workshop provided a useful method for the participants, yielded valuable results and key findings, and identified further tasks for the relevant actors to collaboratively run the business, thereby creating efficient, green transport between Valencia and other hubs (cities and ports).

\section{CONCLUSIONS}

The PAV has set itself the goal of doubling its current rail traffic, which stood at approximately 2.9 million tonnes in 2019 [18], over the next 5 years (2019-2024). Due to this ambitious goal, the PAV is undertaking huge investments to adapt the railway infrastructure of the port and to improve hinterland connectivity through the main railway corridors. Proof of this are the investments made in the Valencia-Zaragoza railway, the adaptation of the rail tracks at the CSP Iberian Valencia Terminal to be able to accommodate trains of up to 750 metres 
in length, the upgrade of the inner railway network of the port or the new railway access and rail terminal in the port of Sagunto, which is also managed by the PAV.

In addition to the infrastructure investments, the PAV is promoting the use of ICT tools and the implementation of new business models that can foster the use of rail transport for cargo. One of the solutions proposed to promote rail for container cargo was the JIT Rail Shuttle Service. The aim of this service is to directly unload containers from the vessel and load them onto the first available shuttle. The financial feasibility of this JIT Rail Shuttle service has been assessed, with the cost per TEU transported being the key success factor for the implementation of this innovative service.

Having demonstrated the financial feasibility, a new collaborative business model for the operation of the JIT Rail Shuttle Service was proposed, with a "SHUTTLE" entity managing both the capacity (trains) and the "slots" (spaces on the train) that are sold to the different railway operators. This business model was discussed by the stakeholders of the Port of Valencia in a workshop that presented the SDBM/R methodology for collaborative business model design. During the session, port community members highlighted the utility of this new methodology for the design of business models, since it allowed them to see in a structured way the actors involved, their main activities to be performed and the costs and benefits associated with each of them. In particular, both the railway operator and the container terminal underlined the important benefits that this new service would bring them. On the one hand, railway operators boost the profitability of their assets by increasing the use of the trains, which allows them to reduce operational costs. On the other hand, port container terminals reduce the number of unnecessary movements in the terminal yard, which translates into lower handling costs per TEU moved. Lower operational costs together with other benefits of the JIT Rail Shuttle Service (e.g. flexibility, frequency and reliability) allow LSPs to offer more competitive services to their customers, who are seeking fast and reliable delivery. In short, the proposed business model has been well received by the main actors involved in the rail processes of the port community of Valencia and the PAV will definitely consider it along with other initiatives to promote rail freight transport in the Port of Valencia. Finally, it should be noted that during the workshop, the main actors involved emphasised the new information flows that would be needed between the different actors to ensure the proper functioning of the service. Recognising this, the PAV underscored that ValenciaportPCS would play a crucial role in the successful implementation of the JIT Rail Shuttle Service.

\section{ACKNOWLEDGEMENTS}

This paper presents some preliminary results of COREALIS (Capacity with a pOsitive enviRonmEntal and societAL footprInt: portS in the future era), which is funded by the European Commission Horizon 2020 Research and Innovation Framework Programme, under Grant Agreement No. 768994. The authors thank Dr. Oktay Türetken (Eindhoven University of Technology) for contributing to the business model development workshop preparation, and the participants of the workshop (held on 16 October 2019 in Valencia) for their contribution: Klaas Rozema (Dynniq, The Netherlands), Thomas Desseilles (ERTICO, Belgium), Georgios Tsimiklis (ICCS, Greece), Giannis Kanellopoulos (ICCS, Greece), Elena Krikigianni (SEAbility, Greece), Susana Caminals (SGS, Spain), Juan Manuel Diez, (Port Authority of Valencia, Spain), Eduardo Orellana (CSP Iberian Valenci.a Terminal, Spain), Jorge Melero (Logitren, Spain) and Patricia Roig (SLISA, Spain). 


\section{REFERENCES}

[1] Notteboom, T. E., \& Rodrigue, J. P. (2005). Port regionalization: towards a new phase in port development. Maritime Policy \& Management, 32(3), 297-313.

[2] Frazzon, E. M., Constante, J. M., Triska, Y., Albuquerque, J. V. D. S., Martinez-Moya, J., Silva, L. D. S., \& Valente, A. M. (2019). Smart port-hinterland integration: conceptual proposal and simulation-based analysis in Brazilian ports. International Journal of Integrated Supply Management, 12(4), 334-352.

[3] Liao, C. H., Tseng, P. H., Cullinane, K., \& Lu, C. S. (2010). The impact of an emerging port on the carbon dioxide emissions of inland container transport: an empirical study of Taipei port. Energy Policy, 38(9), 5251-5257.

[4] Monios, J. (2011). The role of inland terminal development in the hinterland access strategies of Spanish ports. Research in Transportation Economics, 33(1), 59-66.

[5] European Commission, 2011. White Paper on Transport. Roadmap to a Single European Transport Area - Towards a Competitive and Resource-Efficient Transport System. https://ec.europa.eu/transport/themes/strategies/2011_white_paper_en. Accessed on 12 Dec. 2019.

[6] Sáez-Carramolino, L., Sanchez-Pérez, A., Pérez-Cervera, C., Furió-Pruñonosa, S., 2019. Just-In-Time Rail Shuttle Service Feasibility Study in the Port of Valencia. WIT Transactions on The Built Environment, Volume 187, WIT Press, 2019, ISSN 1743-3509.

[7] Sáez-Carramolino, L., Sanchez-Pérez, A., Pérez-Cervera, C., Furió-Pruñonosa, S., 2019. Deliverable D.2.2 Just-In-Time Rail Shuttle Service Feasibility Study. COREALIS Capacity with a pOsitive enviRonmEntal and societAL footprInt: portS in the future era.

[8] Moros-Daza, A., Amaya-Mier, R., \& Paternina-Arboleda, C. (2020). Port community systems: a structured literature review. Transportation Research Part A: Policy and Practice, 133, 27-46.

[9] Osterwalder, A., Pigneur, Y., Clark, T., 2010. Business Model Generation: A Handbook for Visionaries, Game Changers, and Challengers. Strategyzer series. Hoboken, NJ: John Wiley \& Sons.

[10] Grefen, P., 2015. Service-Dominant Business Engineering with BASE/X: Business Modeling Handbook. Amazon CreateSpace.

[11] Grefen, P., O. Turetken, Razavian, M., 2016. Awareness Initiative for Agile Business Models in the Dutch Mobility Sector: An Experience Report. BETA Publication: Working Papers No. 505, Eindhoven University of Technology.

[12] Grefen, P., O. Turetken, K. Traganos, A. den Hollander, Eshuis, R., 2015. Creating Agility in Traffic Management by Collaborative Service-Dominant Business Engineering. IFIP International Federation for Information Processing: PRO-VE 2015 Proceedings, 463, 100-109. Retrieved (http://link.springer.com/10.1007/978-3-319-24141-8).

[13] Sambeek, M., Turetken, O., Ophelders, F., Grefen, P., 2015. Towards an Architecture for Cooperative ITS Applications in the Netherlands. BETA Publication 485. Eindhoven University of Technology.

[14] Traganos, K., P. Grefen, A. den Hollander, O. Turetken, Eshuis, R., 2015. Business Model Prototyping for Intelligent Transport Systems: A Service-Dominant Approach. Beta Publication 469. Eindhoven University of Technology.

[15] Turetken, O., Grefen, P., 2017. Designing Service-Dominant Business Models. In proceedings: European Conference on Information Systems (ECIS 2017). AIS Press. 
[16] Grefen P., Turetken O. (2018) Achieving business process agility through service engineering in extended business networks. BPTrends, April 2018.

[17] Turetken, O., et al., 2019. Business-Model Innovation in the Smart Mobility Domain. In: Lu (Ed.) Cooperative Intelligent Transport Systems Towards High-Level Automated Driving. The Institution of Engineering and Technology (IET), London. DOI: 10.1049/ PBTR025E

[18] Port Authority of Valencia, 2019. Statistical Bulletin November 2019. https://www. valenciaport.com/wp-content/uploads/Bolet\%C3\%ADn-Estad\%C3\%ADsticoNoviembre-2019-PBI.pdf, accessed on 6 Jan. 2020. 